\title{
Utility of urodynamics before surgery for stress urinary incontinence: response to editorial by Lose and Klarskov
}

\author{
S. A. L. van Leijsen - K. B. Kluivers • \\ J. P. F. A. Heesakkers • M. E. Vierhout
}

Published online: 17 May 2014

(C) The International Urogynecological Association 2014

Dear Editor,

We thank the authors for their interest in our study [1]; however, their criticism of the design cannot be shared by us.

First, we would like to draw attention to the fact that the Value of Urodynamics prior to Stress Incontinence Surgery (VUSIS) project consisted of two studies. The authors only refer to the small, underpowered VUSIS I study, even though the larger and adequately powered VUSIS II study was published in early 2013 [2]. The design was different; however, in both studies no benefit from urodynamics (UDS) could be demonstrated. This was also the case in the VALUE study.[3]

In their letter, three large flaws in the study design are presumed:

1. Lack of quality and expertise in UDS. However, quality control was specifically studied and it was shown that the general quality of UDS was high and adequate. The low numbers of 3 UDS performed per center only refers to the VUSIS I study; for the VUSIS II study the mean number was 20.

2. No clear definition of urodynamic entities. We refer in both studies to the ICS standardization reports and used definitions such as those described. There are no clear cut-off values in these definitions. We decided to let the individual doctors make the diagnosis on the basis of UDS. Adding strict, always disputable, cut-off values would have made interpretation of the results even more complex, since not

Related correspondence can be found at doi:10.1007/s00192-014-2402-1 and doi:10.1007/s00192-014-2404-Z

S. A. L. van Leijsen $(\bowtie) \cdot$ K. B. Kluivers · J. P. F. A. Heesakkers • M. E. Vierhout

791, Department of Obstetrics and Gynaecology, Radboud

University Medical Centre, PO Box 9101, 6500 HB Nijmegen, The

Netherlands

e-mail: sanne.vanleijsen@radboudumc.nl the outcome, but the cut-off values for the different entities would have been the points of discussion. By not setting cut-off levels we made the study more representative of daily practice and therefore more clinically meaningful.

3. Treatment strategy. In line with the previous point we feel that, since there are no clear and broadly accepted treatment strategies based on UDS (in fact that was the reason for performing the study), it was essential to give the individual doctors the freedom to decide on the best treatment for individual patients. Again, by doing so, the studies are very representative of daily practice, which would not have been the case if arbitrary cut-off levels or treatment algorithms had been introduced.

In conclusion, we cannot agree with the criticisms of the authors. In their letter they mention their regret that UDS has only made scant progress in the last few decades. We would like to stress that we agree that UDS can be an important diagnostic tool in complex patients; however, not in women with a first episode of demonstrable and, predominantly, stress incontinence, prior to performing a midurethral sling.

Conflicts of interest None.

\section{References}

1. Lose G, Klarskov N (2014) Utility of invasive urodynamics before surgery for stress urinary incontinence. Int Urogynecol J 25:1-3. doi: 10.1007/s00192-013-2163-2

2. Van Leijsen SA, Kluivers KB, Mol BW et al (2013) Value of urodynamics before stress urinary incontinence surgery: a randomized controlled trial. Obstet Gynecol 121(5):999-1008

3. Nager CW, Brubaker L, Litman HJ et al (2012) A randomized trial of urodynamic testing before stress-incontinence surgery. N Engl J Med 366(21):1987-1997 